\title{
Cell-Permeable Bak BH3 Peptide Induces Chemosensitization of Hematologic Malignant Cells
}

\author{
Omar Ugarte-Alvarez ${ }^{(D)},{ }^{1}$ Paola Muñoz-López ${ }^{(D)},{ }^{1,2}$ Liliana Marisol Moreno-Vargas $\mathbb{D}^{3}{ }^{3}$ \\ Diego Prada-Gracia $\left(\mathbb{D},{ }^{3}\right.$ Armando Alfredo Mateos-Chávez $\mathbb{D}^{1}{ }^{1}$ \\ Elayne Irene Becerra-Báez $\mathbb{D}^{1,2}$ and Rosendo Luria-Pérez $\mathbb{D}^{1}$ \\ ${ }^{1}$ Unit of Investigative Research on Oncological Diseases, Children's Hospital of Mexico Federico Gomez, \\ Mexico City 06720, Mexico \\ ${ }^{2}$ Posgrado en Biomedicina y Biotecnología Molecular, Escuela Nacional de Ciencias Biológicas, Instituto Politécnico Nacional, \\ Mexico City 11340, Mexico \\ ${ }^{3}$ Research Unit on Computational Biology and Drug Design, Children's Hospital of Mexico Federico Gomez, \\ Mexico City 06720, Mexico \\ Correspondence should be addressed to Rosendo Luria-Pérez; rluria@himfg.edu.mx
}

Received 30 March 2020; Revised 4 July 2020; Accepted 13 July 2020; Published 30 November 2020

Academic Editor: Vincenzo Coppola

Copyright ( 2020 Omar Ugarte-Alvarez et al. This is an open access article distributed under the Creative Commons Attribution License, which permits unrestricted use, distribution, and reproduction in any medium, provided the original work is properly cited.

\begin{abstract}
Hematologic malignancies such as leukemias and lymphomas are among the leading causes of pediatric cancer death worldwide, and although survival rates have improved with conventional treatments, the development of drug-resistant cancer cells may lead to patient relapse and limited possibilities of a cure. Drug-resistant cancer cells in these hematologic neoplasms are induced by overexpression of the antiapoptotic B-cell lymphoma 2 (Bcl-2) protein families, such as Bcl-xL, Bcl-2, and Mcl-1. We have previously shown that peptides from the $\mathrm{BH} 3$ domain of the proapoptotic Bax protein that also belongs to the $\mathrm{Bcl}-2$ family may antagonize the antiapoptotic activity of the Bcl-2 family proteins, restore apoptosis, and induce chemosensitization of tumor cells. Furthermore, cell-permeable Bax BH3 peptides also elicit antitumor activity and extend survival in a murine xenograft model of human B non-Hodgkin's lymphoma. However, the activity of the BH3 peptides of the proapoptotic Bak protein of the Bcl-2 family against these hematologic malignant cells requires further characterization. In this study, we report the ability of the cellpermeable Bak BH3 peptide to restore apoptosis and induce chemosensitization of acute lymphoblastic leukemia and nonHodgkin's lymphoma cell lines, and this event is enhanced with the coadministration of cell-permeable Bax BH3 peptide and represents an attractive approach to improve the patient outcomes with relapsed or refractory hematological malignant cells.
\end{abstract}

\section{Introduction}

Hematologic malignancies such as acute lymphoblastic leukemia (ALL) and non-Hodgkin's lymphoma (NHL) are among the main causes of death in pediatric cancer patients throughout the world $[1,2]$. These neoplasms arise from the transformation of immature cells in the case of leukemias and of immature or mature cells in lymphomas, mainly compromising the B lymphocyte population and in a lesser proportion that of $\mathrm{T}$ lymphocytes and NK cells [3]. Fortunately, conventional treatments such as chemotherapy and radiotherapy have increased 5-year survival to $92 \%$ in pediatric patients with acute lymphoblastic leukemias and 91\% in pediatric patients with non-Hodgkin's lymphoma [4-6]. However, drug resistance hinders the complete success of these therapies [7]; so, new antitumor therapies must be sought that can completely eradicate drug-resistant transformed cells [8].

Among the mechanisms implicated in cancer drug resistance, there are abnormalities in the genes and proteins of the B-cell lymphoma 2 (Bcl-2) family $[9,10]$ that control the apoptosis mitochondrial pathway. In 
cells, the balance between death and survival is controlled by members of three groups of this family of proteins: the group of multidomain antiapoptotic $\mathrm{BH} 1-4$ proteins (Bcl-2, Bcl- $\mathrm{xL}, \mathrm{Bcl}-\mathrm{w}, \mathrm{Mcl}-1$, and $\mathrm{A} 1$ ) that promote cell survival by inhibiting proapoptotic multidomain proteins; the group of multidomain proapoptotic proteins BH1-3 (BH1-3) (Bax, Bak, and Bok), which are apoptosis effectors; and the group of proapoptotic BH3only proteins (Bid, Bim, Puma, Noxa, Bad, Bmf, Hrk, and Bik) that initiate apoptosis [11-13]. In healthy cells, antiapoptotic proteins bind and inhibit the Bax or Bak effector proteins by blocking their polymerization on the mitochondrial surface and preventing the initiation of apoptosis [11-14]. BH3-only proteins are induced in response to stress signals and promote apoptosis by directly binding to effector proteins or binding to antiapoptotic proteins to release the effector proteins [15]. In this balance, overexpression of antiapoptotic proteins in tumor cells promotes survival of the transformed cell and represents a mechanism of resistance to treatment [16]. Overexpression of antiapoptotic proteins such as Bcl-2, Bcl- $\mathrm{XL}$, and $\mathrm{Mcl}-1$ has found to be associated with drug resistance in human tumor cell lines [17-19], including leukemia [17] and NHL cells [20-23]. The interaction of proteins of the Bcl-2 family through a hydrophobic groove formed by its $\mathrm{BH}$ domains [11-13] has been key in reverting this resistance mechanism.

Peptides derived from the $\mathrm{BH} 3$ domain of proapoptotic proteins have been shown to bind to antiapoptotic proteins, thus antagonizing their function [24-26]. In this context, the use of peptides derived from the $\mathrm{BH} 3$ domain of the Bax and Bad proteins antagonized the activity of the antiapoptotic proteins, $\mathrm{Bcl}-2$ and $\mathrm{Bcl}_{-\mathrm{XL}}$, and induced the release of $\mathrm{cy}-$ tochrome $\mathrm{c}$ from the mitochondria of cells in T-cell acute leukemia [27]; furthermore, when binding the $\mathrm{BH} 3$ domain peptides of the Bax, Bad, and Bak proteins to the fusogenic peptide of the Antennapedia protein (cell-permeable $\mathrm{BH} 3$ peptides) to make them permeable to tumor squamous cells in carcinoma of the head and neck and in T-cell acute leukemia cells, they blocked the activity of $\mathrm{Bcl}_{-\mathrm{XL}}$ and $\mathrm{Bcl}-2$, restoring apoptosis [28]. We have previously reported that bactofection of plasmids encoding a peptide from the $\mathrm{BH} 3$ domain of the proapoptotic Bax protein, antagonized the antiapoptotic activity of the Bcl-2 family proteins, restored apoptosis, and induced chemosensitization of tumor cells [29], and we have recently documented that a cell-permeable $\mathrm{Bax} \mathrm{BH} 3$ peptide expressed and released into the tumor microenvironment via a live-attenuated bacterial vector promoted apoptosis, induced antitumor activity, and increased survival in a murine xenograft model of human B non-Hodgkin's lymphoma [30]. However, the activity of the $\mathrm{BH} 3$ peptides of the proapoptotic Bak protein of the $\mathrm{Bcl}-2$ family against these hematologic malignant cells requires further characterization. In this study, we report the ability of the Bak BH3 peptide coupled with the Antennapedia fusogenic peptide (cell-permeable Bak BH3 peptide) to promote apoptosis and induce chemosensitization of acute lymphoblastic leukemia and non-Hodgkin lymphoma cell lines.

\section{Materials and Methods}

2.1. Molecular Modeling by Homology. To generate the model of the cell-permeable Bak BH3 peptide, APTK chimera (Antennapedia fusogenic peptide $=\mathrm{AP}$, Flag peptide $=\mathrm{T}$, and $\mathrm{Bak} \mathrm{BH} 3$ peptide $=\mathrm{K}$ ), we used two independent strategies and then chose the consensus model. On the one hand, we used an assembly of large rigid fragments obtained from similar structures aligned by means of their primary and secondary sequences. This methodology cuts and pastes fragments of the peptide skeleton of known structures (SWISS-MODEL) [31, 32]. On the other hand, we used modeling satisfying the molecular constraints extracted from databases and similarly aligned structures. This method helps produce a set of structures for the A sequence, all of which are compatible with the restrictions observed in the templates (MODELLER) [33, 34].

2.2. Geometry Optimization of the Proposed Models. Once the 3D models were prepared, hydrogen atoms were added, and side-chain orientations were optimized through the energy minimization steepest descent method, using the CHARMM36 force field [35] in a TIP3P water box [36] with the molecular dynamics engine OpenMM [37].

2.3. Stereochemical Quality Evaluation of the Models. Coordinate files of the 3D models were sent to MolProbity [38] to produce a Ramachandran plot ( $\phi$ and $\psi$ angles) reflecting polypeptide chain distortion in the nonfully allowed region. We also sent the coordinate files to RAMPAGE to identify side chains with less common conformations possibly because of local protein tension [39]. The quality of the models was further validated using two additional tools: ProQ3/ProQ3D [40, 41] and QMEAN [42].

2.4. Peptides and Drugs. The peptide sequences used in our study are as follows: for the $\mathrm{BH} 3$ domain peptide of the Bak protein $(\mathrm{K})$, we used the sequence MGQVGRQLAIIGDDINRRY [28], for the BH3 domain peptide of the Bax protein, we used the sequence STKKLSECLKRIGDELDSN (X) [30], for the Flag peptide, we used the sequence DYKDDDDK (T) [43], and for the Antennapedia fusogenic peptide, we used the sequence RQIKIWFQNRRMKWKK (PE), also known as Penetratin [28]. The peptides used in this study were synthesized by Peptide 2.0 Company, USA. The negative control peptides were PET $=$ RQIKIWFQNRRMKWKKDYKDDDDK and KT = MGQVGRQ LAIIGDDINRRYDYKDDDDK and the peptide complexes of the cell-permeable Bak peptide PETK $=$ RQIKIWFQN RRMKWKKDYKDDDDKMGQVGRQLAIIGDDINRRY and cell-permeable Bax peptide PEX=RQIKIWFQ NRRMKWKKSTKKLSECLKRIGDELDSNM. All peptides were diluted in sterile water. The drug cisplatin (CDDP, cisdiamino-dichloro-platin II) from Sigma-Aldrich was diluted in dimethylsulfoxide (DMSO). Vincristine (Sigma-Aldrich) was diluted in sterile water. 
2.5. Cell Lines and Cell Cultures. The Ramos RA1 cell line (Burkitt's lymphoma), a human B non-Hodgkin's lymphoma (ATCC, CRL-1596), and a CCRF-CEM cell line of human T acute lymphoblastic leukemia (ATCC, CCL-119) were obtained from the American Type Cell Collection and cultured in advanced RPMI 1640 medium (Invitrogen), supplemented with $1 \%$ antibiotics-antimycotics, with $10000 \mathrm{U} / \mathrm{mL}$ penicillin $\mathrm{G}, 10 \mathrm{mg} / \mathrm{mL}$ streptomycin, $25 \mu \mathrm{g} / \mathrm{mL}$ amphotericin B, and $4 \%$ fetal bovine serum (FBS, Invitrogen). Cultures were permanently maintained at $37^{\circ} \mathrm{C}$ and $5 \% \mathrm{CO}_{2}$. For the infection assays, the cells were grown with advanced RPMI 1640 medium (Invitrogen) and supplemented with $2 \%$ FBS without antibiotics (Invitrogen). Peripheral blood mononuclear cells (PBMC) from healthy donors were obtained from the blood bank of the Children's Hospital of Mexico Federico Gomez, isolated by FicollPaque Plus (GE Healthcare Life Sciences), and cultured under Ramos cells conditions.

2.6. Detection of the Antiapoptotic and Proapoptotic Molecules by Western Blot. Detection of the antiapoptotic and proapoptotic molecules was conducted with slight modifications to the technique described by Mateos-Chavez et al. [30]. A million Ramos or CCRF-CEM cells were lyzed with RIPA lysis buffer (Sigma-Aldrich) supplemented with a cocktail of protease inhibitors (Roche). Protein quantification was performed with the bicinchoninic acid kit by Thermo Fisher Scientific. For the Western blot, $40 \mu \mathrm{g}$ of total protein was placed in each well, and electrophoresis on 15\% polyacrylamide-SDS gel was performed. The proteins were then transferred to nitrocellulose membranes (Bio-Rad) with a Trans-Turbo Blot System by Bio-Rad (25 volts, 10 minutes). For the detection of the $\mathrm{Bcl}_{-\mathrm{xL}}$, Mcl-1, Bcl-2, Bak, and $\mathrm{Bax}$ proteins, we used anti-Bcl-${ }_{\mathrm{XL}}$, anti-Mcl-1, anti-Bak, and anti-Bax antibodies (cell signaling) induced in rabbits and anti-Bcl-2 (cell signaling) induced in mouse, all of them diluted 1:500 in blocking buffer (Li-Cor), and as the secondary antibody, goat anti-rabbit IgG IR Dye $800 \mathrm{cw}$ and goat anti-mouse $680 \mathrm{cw}$ (Li-Cor) diluted $1: 10000$ in blocking buffer (Li-Cor). As a constitutive protein control, we used an anti- $\beta$-tubulin antibody (Abcam), induced in rabbit and diluted at 1:8000 in blocking buffer (Li-Cor). Finally, the image was obtained and analyzed in the system for infrared fluorescent imaging, Odyssey CLx (Li-Cor).

2.7. Treatment of Ramos and CCRF-CEM Cells with the Peptides and/or the Drug Cisplatin. The Ramos and CCRFCEM were treated with $20 \mu \mathrm{M}$ [44] of the different peptides for 12 hours, in the presence or absence of the drug cisplatin (CDDP) $40 \mu \mathrm{M}$. The cells were then subjected to various protocols to evaluate cellular viability and apoptosis.

2.8. Cell Viability Assay. Twenty thousand Ramos and CCRF-CEM cells were cultured in 96-well plates with $20 \mu \mathrm{M}$ of the PETK, PET, and KT peptides, with or without cisplatin, $40 \mu \mathrm{M}$. After 12 hours of treatment, the cells were processed to determine viability with the MTT (3-(4, 5-dimethylthiazol-2)-2, 5-diphenyltetrazolium bromide)), according to the manufacturer's instructions (Roche). Briefly, $10 \mu \mathrm{L}$ of the MTT reagent was added to the wells with treated and untreated cells; they were then incubated for 4 hours at $37^{\circ} \mathrm{C}$ and $5 \% \mathrm{CO}_{2}$. Subsequently, $100 \mu \mathrm{L}$ of the solubilizing reagent was added to each well, and these were incubated overnight at $37^{\circ} \mathrm{C}$ and $5 \% \mathrm{CO}_{2}$. Finally, they were read at $550 \mathrm{~nm}$ in an EnSpire plate multireader (Perkin Elmer).

2.9. Evaluation of Caspase 3 Activity by Flow Cytometry. These assays were conducted with modifications to the protocol described by Mateos-Chávez et al. [30]. After treatment of the Ramos and CCRF-CEM cells (200,000 cells) with the different peptides at $20 \mu \mathrm{M}$, with or without cisplatin $40 \mu \mathrm{M}$, cells were washed, fixed, and permeabilized for intracellular staining with active anti-caspase-3 antibodyFITC (BD Pharmingen). Data collection and analysis were conducted in a CytoFLEX (Beckman Coulter) cytometer.

2.10. Statistical Analysis. To determine the differences between cell groups treated with the different peptides, we used one-way analysis of variance (ANOVA) and post hoc Bonferroni tests, with a 95\% confidence interval. In all cases, the average of three or more independent experiments is presented \pm the standard deviation (SD). Differences were considered significant at $p$ values $\leq 0.05$ in all comparisons. Statistical analysis was performed with GraphPad Prism 6 and IBM SPSS Statistics software.

\section{Results}

3.1. 3D Structure of the Cell-Permeable Bak BH3 Peptide. In order to predict the folded and partially misfolded regions of the cell-permeable Bak $\mathrm{BH} 3$ peptide, as well as to contribute to a better description, a molecular modeling and geometry optimization of the tridimensional structure of the cell-permeable Bak BH3 peptide (PETK) was conducted with chemoinformatic techniques. The three-dimensional model is characterized by having two $\alpha$-helices connected by a loop. In general, a helix is smaller (Bak BH3 peptide $=K$ ), and due to the flexibility of the loop (Tag peptide $=\mathrm{T}$ ), it allows the $\mathrm{Bak} \mathrm{BH} 3$ peptide to dimerize with the larger helix, Antennapedia fusogenic peptide (PE) (Figure 1). The folding and packing allow the visualization of a structural domain of the bHLH type. Stereochemical quality evaluation revealed that $99.8 \%$ of the residues are in zones that correspond to nuclear regions, representing physically accessed conformations to $\alpha$-helices. As a result of this evaluation, we were able to determine that only one residue in the model (Ile35) is out of the fully allowed areas of the Ramachandran plot. When performing a theoretical prediction on the internalization of the core in the membrane, we observed that given its amino acid composition and its hydrophobicity, it is possible that it crosses the membrane through a diffusion process (data not shown). 


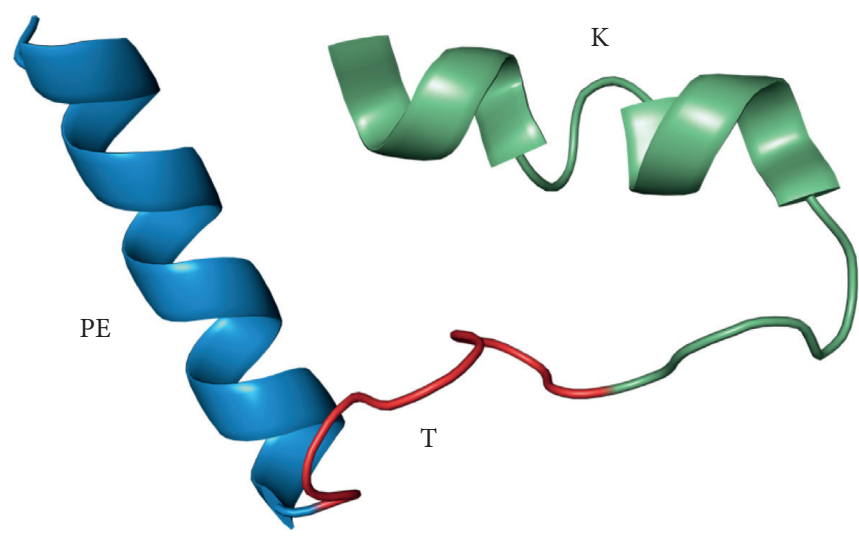

(a)

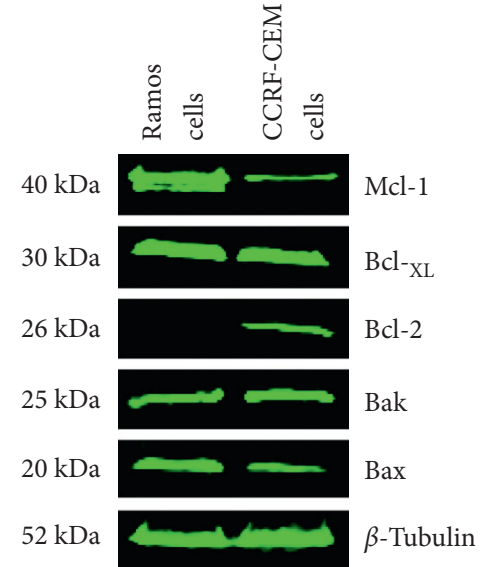

(b)

FIGURE 1: 3D structure of cell-permeable Bak BH3 peptide (PETK) and expression of the Bcl-2 family proteins in hematologic malignant cells. (a) The structure is characterized by having two $\alpha$-helices connected by a loop. The folding and packing allow the visualization of a structural domain of the bHLH type: a minor helix (Bak BH3 peptide $=\mathrm{K}$ ) that folds towards the major basic helix (Antennapedia fusogenic peptide $=\mathrm{PE})$ due to the flexibility of the loop $($ Tag peptide $=\mathrm{T})$; its strong negative charge directs the packaging of the polypeptide. $(\mathrm{b})$ Expression of the antiapoptotic proteins (Mcl-1, Bcl- ${ }_{-\mathrm{LL}}$, and Bcl-2) and proapoptotic proteins (Bak and Bax) in Ramos (NHL) and CCRFCEM (ALL) cells. Proteic extracts of hematologic malignant cells ( $40 \mu \mathrm{g}$ per well) were analyzed by Western Blot using the anti-Mcl-1, anti$\mathrm{Bcl}_{-\mathrm{XL}}$, anti-Bcl-2, anti-Bak, anti-Bax, and anti- $\beta$-tubulin antibodies. Goat anti-rabbit IgG antibody (IRDye ${ }^{\circledR}$ Odyssey) was used as a secondary antibody.

3.2. Cell-Permeable Bak BH3 Peptide Induces ApoptosisMediated Cell Death in Hematologic Malignant Cell Lines. To analyze the ability of the cell-permeable Bak $\mathrm{BH} 3$ peptide to induce cell death by apoptosis in malignant hematologic cell lines, we conducted cell viability assays and active caspase-3 determinations. Thus, Ramos and CCRF-CEM cells expressing the antiapoptotic proteins $\mathrm{Mcl}-1, \mathrm{Bcl}_{-\mathrm{XL}}$, and $\mathrm{Bcl}-2$ and the proapoptotic proteins $\mathrm{Bax}$ and $\mathrm{Bak}$ (Figure 1(b)) were treated with the peptides PET, KT, and PETK for $12 \mathrm{~h}$ at a concentration of $20 \mu \mathrm{M}$ and evaluated with the MTT cell viability assay. Untreated cells (medium) and cells treated with the vehicle (DMSO), in which CDDP is dissolved, were used as negative controls, and the positive control was cisplatin (CDDP, a drug used in some cases of refractory non-Hodgkin's lymphoma) [45, 46]. Figure 2(a) shows a significant decrease in Ramos cell viability (NHL) after treatment with our peptide of interest, PETK $(62.43 \% \pm 2.5)$. The CDDP-positive control decreased their viability to average values of $76.4 \% \pm 1$, while the control peptides PET and KT also showed a slight decrease in viability to values of $87.7 \% \pm 0.96$ and $92.23 \% \pm 2$, respectively. Surprisingly, a greater effect was observed in CCRF-CEM (ALL) cells in terms of viability, after treatment with the PETK peptide $(36.4 \% \pm 2)$, almost $26 \%$ more than that observed in Ramos cells. Cells treated with CDDP decreased their viability to values of $55.96 \% \pm 2.61$, close to $15 \%$ more than in Ramos cells, suggesting that CCRF-CEM cells are more sensitive to chemotherapeutic treatment and even to the PETK peptide.

Subsequently, we examined whether the decrease in cell viability was mediated by the induction of apoptosis. For this purpose, Ramos and CCRF-CEM cells were treated with the different peptides at $20 \mu \mathrm{M}$ for 12 hours and subjected to apoptosis assays such as active caspase-3. As positive controls, cells were treated with $40 \mu \mathrm{M}$ CDDP, and as negative controls, untreated cells (medium) and cells with DMSO were used. Figure 2(b) shows that Ramos cells treated with the PETK peptide had a greater number of active caspase- 3 cells $(20.25 \% \pm 0.3)$ compared with the other treatments. In this assay, cells treated with CDDP at $40 \mu \mathrm{M}$ were positive for active caspase- 3 in $14.9 \% \pm 2.7$, while the PET $(5.2 \% \pm 2.0)$ and KT $(3.5 \% \pm 1.3)$ peptides have very similar baseline values to untreated cells suspended only in medium $(5.0 \% \pm 0.0)$. In the case of CCRF-CEM cells (Figure 2(b)) treated with the PETK peptide, there was a greater number of active caspase- 3 positive cells $(45.6 \% \pm 1.1)$ compared with untreated cells $(5.0 \% \pm 0.0)$, while in cells treated with PET $(7.1 \% \pm 1.5)$ and KT $(6.2 \% \pm 1.5)$, there were no significant differences compared with untreated cells. In the group treated with CDDP as a positive control, we obtained only $26.9 \% \pm 3.6$ of active caspase- 3 positive cells. These results show that as in Ramos cells, the CCRF-CEM treated with the PETK peptide significantly increased the apoptosis when compared with the cells treated with the chemotherapy drug CDDP and other controls. It is important to mention that these data confirm that CCRF-CEM cells are more sensitive than Ramos cells to treatment with the PETK peptide and the drug CDDP.

\subsection{Cell-Permeable Bak BH3 Peptide Induces Chemo-} sensitization of Hematologic Malignant Cell Lines. Treatment failure in patients with hematologic malignancies is not only mediated by drug resistance but is also associated with drug toxicity; solving this problem is a great challenge in the clinic. One of the strategies to damper this issue is the subtoxic administration of drug doses in conjunction with molecules that sensitize tumor 


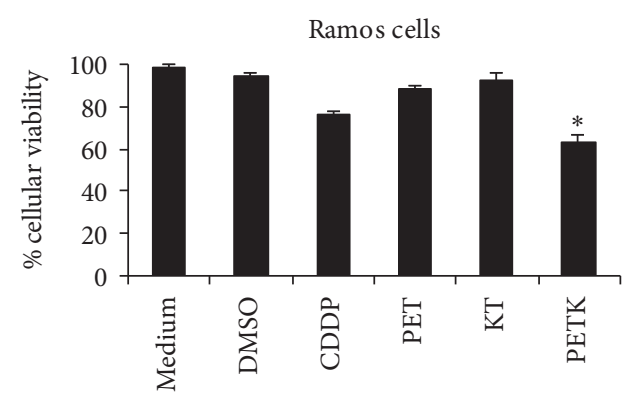

Treatment

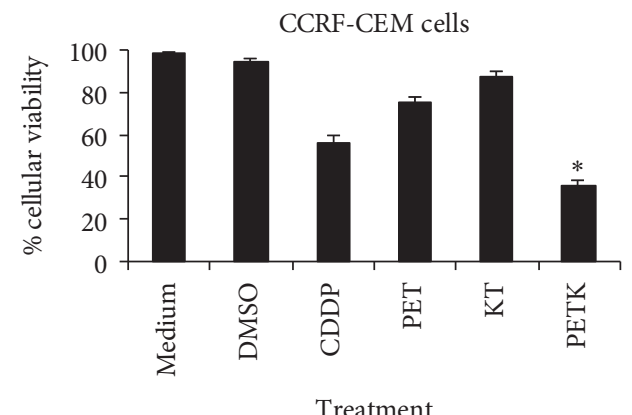

(a)
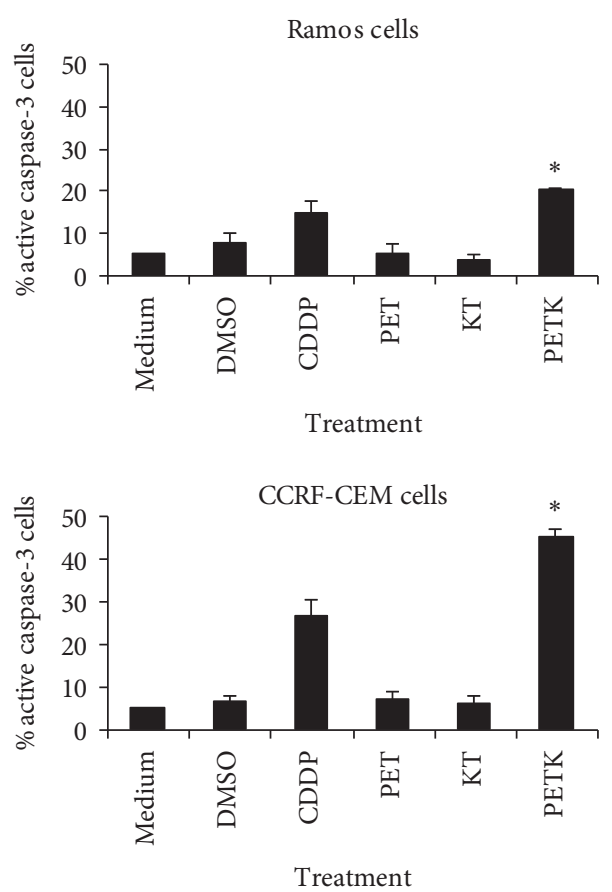

(b)

Figure 2: The cell-permeable Bak BH3 peptide decreases the viability and increases apoptosis in hematological malignant cell lines. (a) Cell viability assays. Ramos and CCRF-CEM cells were incubated for $12 \mathrm{hrs}$ with $20 \mu \mathrm{M}$ of the PET, KT, and PETK peptides. Cisplatin (CDDP) $40 \mu \mathrm{M}$ was used as a positive control. Viability was analyzed with MTT. Bar graphs represent the average \pm SD of three independent experiments. An ANOVA test was conducted with a post hoc Bonferroni test to calculate the $p$ value between the study groups. A significant difference was observed between the cells treated with the PETK peptide compared with the other controls $\left({ }^{*} p<0.05\right)$. (b) Apoptosis assays. Ramos and CCRF-CEM cells were incubated for $12 \mathrm{hrs}$ with $20 \mu \mathrm{M}$ of the PET, KT, and PETK peptides, using cisplatin $40 \mu \mathrm{M}$ as a positive control. Apoptosis was quantified with an active caspase-3 assay and analyzed by flow cytometry. The graphs represent the values obtained in three independent assays. An ANOVA test was performed with a post hoc Bonferroni test to establish differences between groups. ${ }^{*} p<0.05$.

cells to die by apoptosis. Hence, we analyzed the ability of the cell-permeable Bak BH3 peptide (PETK) to induce sensitization to chemotherapy, particularly to cisplatin (CDDP), a drug used in the management of some cases of refractory hematologic malignancies $[45,46]$. Considering that the experimentally determined toxic dose 50 (TD50) of CDDP in Ramos cells was $167 \mu \mathrm{M}$ and $37 \mu \mathrm{M}$ in CCRF-CEM cells after 12 hours of treatment (data not shown), and we used $40 \mu \mathrm{M}$ of this drug as a subtoxic dose to analyze the sensitivity to chemotherapy induced by the cell-permeable Bak $\mathrm{BH} 3$ peptide. We, therefore, treated Ramos and CCRF-CEM cells for $12 \mathrm{hrs}$ with the different peptides, at $20 \mu \mathrm{M}$, with or without cisplatin $40 \mu \mathrm{M}$ and then performed cell viability assays by MTT and apoptosis by active caspase-3. As shown in Figure 3(a), the Ramos cells treated with the cell-permeable Bak $\mathrm{BH} 3$ peptide in the presence of CDDP, considerably decreased in terms of cellular viability to $37.3 \% \pm 1.4$, which represents $25 \%$ less viability than in cells that were only treated with the PETK peptide $(62.4 \% \pm 3.6)$, and $40 \%$ less than that of cells that were only treated with $\operatorname{CDDP}(76.4 \% \pm 1.4)$. In the case of CCRF-CEM cells treated with the cell-permeable $\mathrm{Bax} \mathrm{BH} 3$ peptide and $\mathrm{CDDP}$, cell viability also decreased considerably to $20.2 \% \pm 1.8,16 \%$ less viability than cells that were only treated with the PETK peptide
$(36.42 \% \pm 2.8)$, and $35 \%$ less than the cells treated with only CDDP $(55.99 \% \pm 3.7)$. The controls, medium, DMSO, PET, and KT peptides had baseline cell viability values above $90 \%$.

To analyze whether this increase in sensitivity to chemotherapy was mediated by an increase in apoptosis, we determined the percentage of active caspase- 3 positive Ramos and CCRF-CEM cells treated with the peptides in the presence or absence of CDDP. Figure 3(b) shows a clear increase in the percentage of active caspase- 3 positive Ramos cells after treatment with the PEXT peptide and cisplatin (39.252 \pm 1.3 ), compared with those that were only treated with the PEXT peptide $(20.25 \pm 0.3)$, or only with cisplatin $(14.9 \pm 2.7)$. Cells treated with the controls, medium, DMSO, and the PET and KT peptides established the baseline apoptosis values. Data obtained with the CCRFCEM cells also confirmed an increase in apoptosis after treatment with the PEKT peptide in the presence of cisplatin $(64.8 \% \pm 3.11)$, in comparison with the cells that were only treated with PEKT $(45.6 \% \pm 1.5)$ or CDDP $(26.96 \% \pm 3.6)$. Cells treated with the controls, medium, DMSO, PET and KT peptides established the apoptosis baseline values. These results confirmed the ability of the cell-permeable Bak $\mathrm{BH} 3$ peptide to chemosensitize hematologic malignancy cells. 


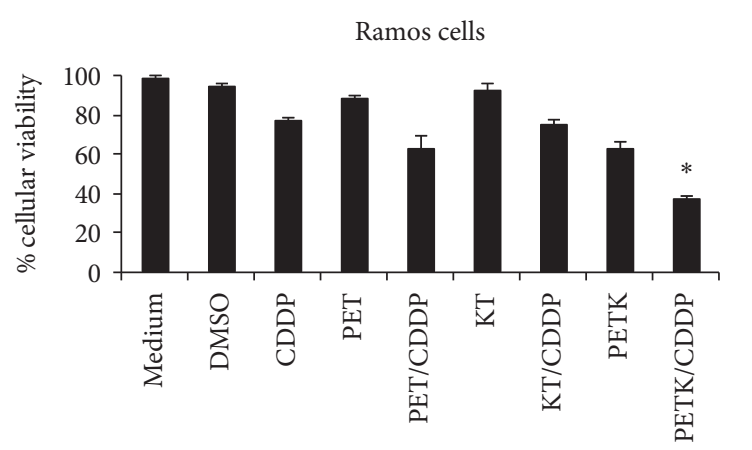

Treatment

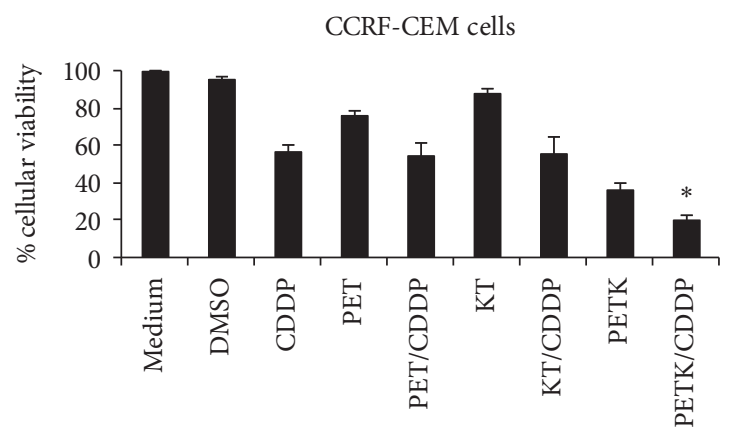

Treatment

(a)

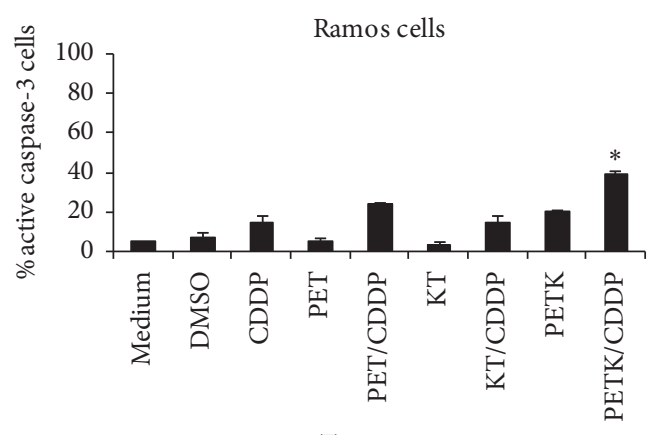

Treatment

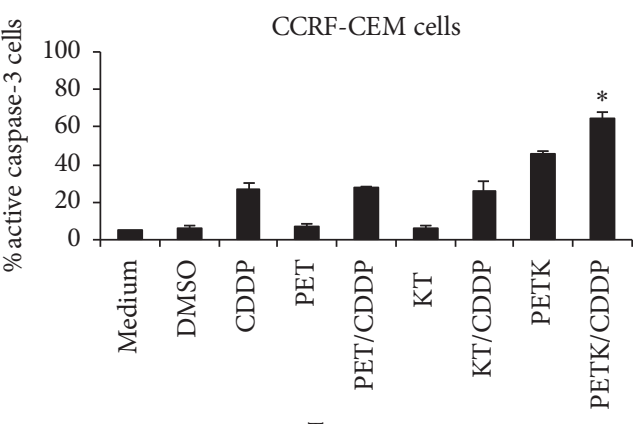

Treatment

(b)

FIgURE 3: Sensitivity to chemotherapy mediated by the cell-permeable Bak BH3 peptide. Ramos and CCRF-CEM cells were incubated for $12 \mathrm{hrs}$ with $20 \mu \mathrm{M}$ of the PEKT, PET, and KT peptides, in the presence or absence of cisplatin (CDDP) $40 \mu \mathrm{M}$. (a) Cell viability was analyzed with MTT assays. (b) Apoptosis was quantified with the active caspase- 3 assay and analyzed by flow cytometry. In both assays, the graphs represent the values of three independent assays. An ANOVA test was performed with Bonferroni post hoc analysis to establish the difference between groups. ${ }^{*} p<0.05$.

3.4. Cell-Permeable BH3 Peptides from Proapoptotic Bak and Bax Proteins Increase Cell Death in Hematologic Malignant Cell Lines. Considering the synergistic effect on death induction in tumor cells after the administration of two $\mathrm{BH} 3$ peptides from proapoptotic proteins or two synthetic BH3 mimetics [47-49], we established whether the combination of the cell-permeable Bak BH3 peptide (PETK) and the cell-permeable Bax BH3 peptide (PEX) could increase death in malignant hematologic cells. Thus, Ramos and CCRF-CEM cells were treated with $20 \mu \mathrm{M}$ of the different peptides and incubated for 12 hours. Figure 4(a) reveals the significant decrease in Ramos cell viability after treatment with both PETK and PEX peptides, with values of $21.84 \pm 1.4$, reflecting $41 \%$ less viability than in cells that were only treated with the PETK peptide $(63.49 \% \pm 6.0)$, $20 \%$ less viability than the cells that were only treated with the PEX peptide $(42.37 \% \pm 0.8)$, or $51 \%$ less when compared with the positive CDDP control $(74.33 \% \pm 1.1)$. In CCRFCEM cells, we observed a more dramatic effect in the decrease in cell viability after treatment with the combination of PETK and PEX peptides $(9.93 \pm 1.2)$, a value equivalent to $30 \%$ less cellular viability than that observed in the cells treated with PETK $(40.00 \% \pm 1.5), 12 \%$ less viability than cells treated with PEX $(21.98 \% \pm 0.9)$, or $47 \%$ less viability than the positive CDDP control $(57.30 \% \pm 2.6)$.
In order to analyze the toxicity of the peptides used in this study on normal cells, peripheral blood mononuclear cells (PBMC) were treated with the different peptides for 12 hours and analyzed for cell viability assays with MTT; results showed a slight decrease in cell viability, with over $90 \%$ of live cells after treatment with the PEXT, PET, KT, X, and PEX peptides (Figure 4(b)). Overall, these results confirm that the combination of cell-permeable Bak $\mathrm{BH} 3$ peptide and the cell-permeable Bax $\mathrm{BH} 3$ peptide have a synergistic effect on the induction of cell death in hematologic malignant cell lines and that the peptides described in the study do not mediate a cytotoxic effect on normal cells such as PBMC.

3.5. Enhanced Chemosensitization of Hematologic Malignant Cell Lines Mediated by the Combination of Cell-Permeable Bak and Bax BH3 Peptides. Once the ability of the combination of cell-permeable Bak and Bax BH3 peptides was shown to promote death in $78 \%$ of Ramos cells and $90 \%$ of CCRF-CM cells, better than the chemosensitization efficacy of the hematologic malignancies in the presence of the cell-permeable Bak BH3 peptide and cisplatin, we analyzed whether the combination of these peptides further increased sensitization to chemotherapy in hematologic malignant cells.

Thus, Ramos and CCRF-CEM cells were treated with the different peptides and the combination of the cell-permeable 


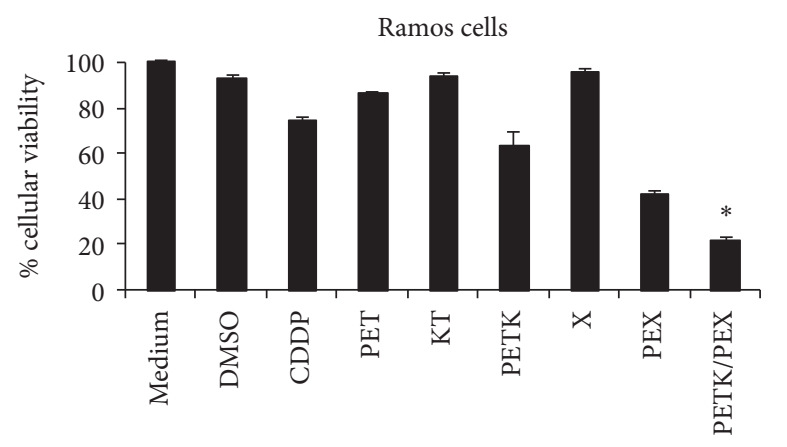

Treatment

Treatment

(a)
CCRF-CEM cells

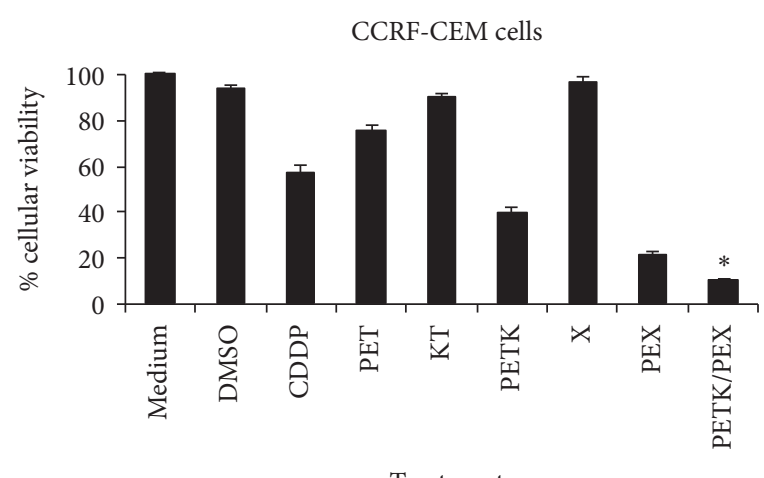

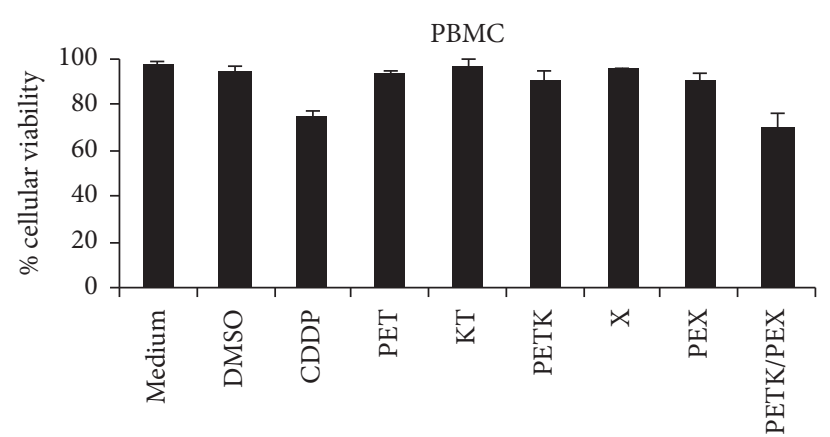

Treatment (b)

Figure 4: The combination of cell-permeable Bak and Bax BH3 peptides increases cell death of hematologic malignant cell lines. (a) Ramos and CCRF-CEM cells were incubated for $12 \mathrm{hrs}$ with $20 \mu \mathrm{M}$ of the PETK, PET, KT, X, and PEX peptides and the PETK and PEX combination. CDDP $40 \mu \mathrm{M}$ was used as a positive control. (b) Peripheral blood mononuclear cells (PBMC) were incubated for $12 \mathrm{hrs}$ with $20 \mu \mathrm{M}$ of the PETK, PET, KT, X, and PEX peptides and with the PETK and PEX combination. CDDP $40 \mu \mathrm{M}$ was used as a positive control. In both cases, cell viability was determined with MTT assays. The graphs represent the value of three independent assays. The ANOVA test was performed with Bonferroni post hoc analysis to determine the difference between groups. ${ }^{*} p<0.05$.

Bak BH3 peptide (PETK) plus the cell-permeable Bax BH3 peptide (PEX), in the presence of a subtoxic dose of vincristine, a commonly used drug in the management of hematologic malignancies [50]. The experimentally determined toxic dose 50 (TD50) of vincristine in Ramos cells was $280 \mathrm{nM}$ and $177 \mathrm{nM}$ in CCRF-CEM cells (data not shown). Based on these results, Ramos and CCRF-CEM cells were treated for $6 \mathrm{hr}$ with the PET, KT, and PETK peptides at $20 \mu \mathrm{M}$ and with the X and PEX peptides at $5 \mu \mathrm{M}$ (the dose of these peptides was decreased to underscore the synergistic effect in inducing tumor cell death), in the presence or absence of the subtoxic dose of vincristine, $80 \mathrm{nM}$; they were then tested for cell viability by MTT. Figure 5 shows that the Ramos cells had a slight decrease in cell viability in response to vincristine treatment $(76.18 \% \pm 1.6)$, cell-permeable Bak $\mathrm{BH} 3$ peptide $(82.80 \% \pm 1.0)$, or the cell-permeable $\mathrm{Bax} \mathrm{BH} 3$ peptide $(76.42 \% \pm 0.7)$, and that treatment with both cell-permeable BH3 peptides (PETK and PEX) significantly decreased cell viability to values of $48.5 \% \pm 5.4$, that further decreased by $20 \%$ in the presence of vincristine $(28.5 \% \pm 2.9)$. It is important to mention that the cells treated with the PETK $(61.0 \pm 4.4)$ or PEX $(63.31 \pm 2.0)$ peptides in the presence of vincristine only had a moderate decrease in cell viability, as expected.
In CCRF-CEM cells, we observed a moderate decrease in cell viability after treatment with vincristine $(66.17 \% \pm 2.7)$, cell-permeable Bak BH3 peptide $(69.10 \% \pm 5.7)$, or the cellpermeable Bax $\mathrm{BH} 3$ peptide $(62.13 \% \pm 0.7)$, and treatment with both cell-permeable $\mathrm{BH} 3$ peptides (PETK and PEX) significantly decreased cell viability to values of $32.02 \% \pm 2.8$. This decrease dramatically increased by $14 \%$ in the presence of vincristine $(18.4 \% \pm 4.4)$. Cells treated with the PETK $(59.26 \pm 3.4)$ or PEX $(43.19 \pm 1.5)$ peptides in the presence of vincristine showed a moderate decrease in cell viability, as expected. Overall, these results show that treatment with the combination of the cell-permeable Bak and Bax BH3 peptides increases chemosensitization in hematologic malignant cells.

\section{Discussion}

Worldwide, hematologic malignances are among the first causes of death in the pediatric population, although treatment with chemotherapy multiagents has increased survival to 5 years in non-Hodgkin's lymphoma (NHL) in $85 \%$ of cases $[5,6]$, and in $95 \%$ of cases of acute lymphoblastic leukemia (ALL) [51], close to $20 \%$ of the population with these neoplasms fails treatment, relapse, and dies [51]. This less than favorable scenario has led to the research and 

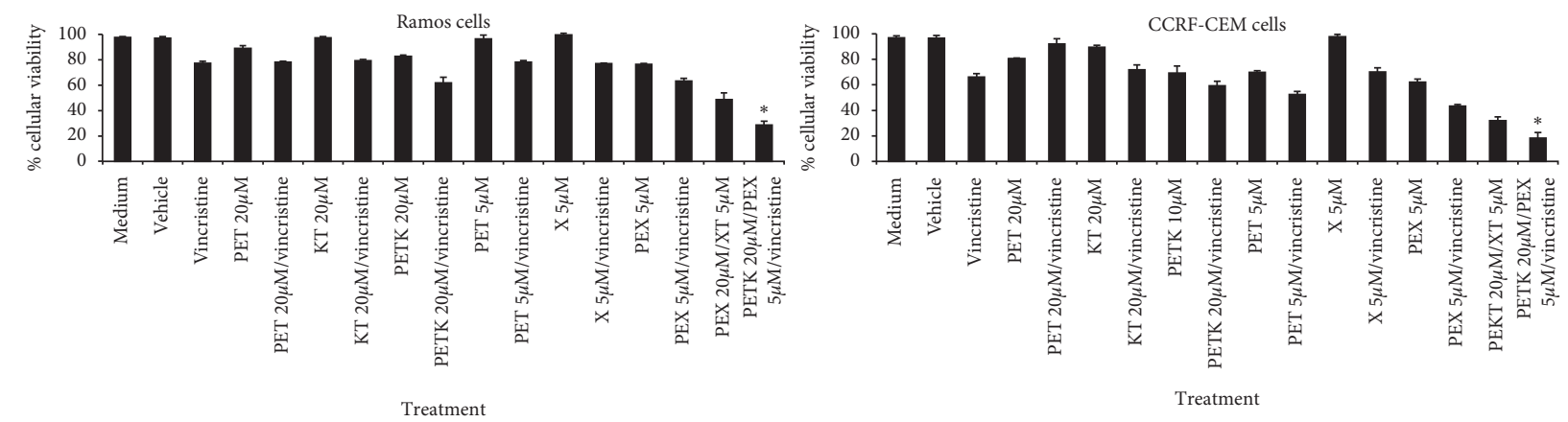

FIGURE 5: The combination of cell-permeable BH3 peptides enhances chemotherapy sensitivity in hematologic malignant cell lines. Ramos and CCRF-CEM cells were incubated for 6 hrs with $20 \mu \mathrm{M}$ of the PEKT, PET, and KT peptides and $5 \mu \mathrm{M}$ of the X and PEX peptides and the combination of PEXT and PEX. Vincristine $80 \mathrm{nM}$ was the chemotherapeutic agent. In both cases, cell viability was determined with MTT assays. The graphs represent the values of three independent assays. The ANOVA test was performed with Bonferroni post hoc analysis to establish the difference between groups. ${ }^{*} p<0.05$.

development of new antitumor therapies that can completely eradicate drug-resistant transformed cells [8]. Among the causes of treatment failure, drug resistance is pivotal [7] and can be mediated by the dysregulation of genes and proteins of the Bcl-2 family that play a key role in intrinsic apoptosis $[9,10]$. In healthy cells, antiapoptotic proteins from the Bcl-2 families, such as Bcl-2, Bcl- $\mathrm{xL}$, and Mcl-1 among others, bind to and inhibit the effector proteins Bax or Bak, blocking their polymerization on the mitochondrial surface and preventing the initiation of apoptosis [14]. Based on this required balance, the overexpression of antiapoptotic proteins in tumor cells promotes the survival of the transformed cell and represents a mechanism of treatment resistance [16]. In NHL and ALL, overexpression of the antiapoptotic proteins Bcl-2 [20, 21, 52], Bcl- $\mathrm{xL}$ $[22,23,52]$, and Mcl-1 [52, 53] have been documented to be associated with drug resistance. Reverting this resistance mechanism has been possible due to the structural studies that reveal that proteins from the Bcl-2 family interact between themselves via a hydrophobic groove formed by its $\mathrm{BH}$ domains [11-13]; in this way, $\mathrm{BH} 3$ domain-derived peptides from proapoptotic proteins can bind to the antiapoptotic proteins and antagonize their function [24-26].

On this basis, $\mathrm{BH} 3$ domain hydrophobic peptides of the $\mathrm{Bax}, \mathrm{Bad}$, and Bak proteins once coupled to the Antennapedia fusogenic peptide (cell-permeable Bax BH3 peptides) to make them permeable to squamous cell carcinoma tumor cells and T-cell acute leukemia cells, blocking the activity of $\mathrm{Bcl}_{-\mathrm{XL}}$ and $\mathrm{Bcl}-2$ and restoring apoptosis [28]. Other studies have documented that the use of peptides from the $\mathrm{BH} 3$ region of the BIM protein is effective in the treatment of cell lines from refractory hematologic malignancies [54], and the use of small molecules that mimic the function of the BH3-only proteins in the treatment of refractory hematologic malignancies has been also explored [55], as in the case of ABT-737 [56, 57] and its orally bioavailable derivatives, ABT-263/navitoclax [58] (both bind with high affinity to $\mathrm{Bcl}-2, \mathrm{Bcl}_{-\mathrm{XL}}$, and Bcl-w), GX15-070/ obatoclax [59] (an inhibitor targeting all antiapoptotic Bcl-2 family proteins), and ABT-199/venetoclax (a Bcl-2 antagonist), and this last was recently approved by the FDA for the treatment of chronic lymphocytic leukemia (CLL) but not of non-Hodgkin's Lymphoma [15, 44]. We have previously reported that the bactofection of sequences encoding a peptide from the $\mathrm{BH} 3$ domain of the proapoptotic Bax protein, antagonized the antiapoptotic activity of the Bcl-2 family proteins, restored apoptosis, and induced chemosensitization of tumor cells [29]; also, we recently reported that a cell-permeable $\mathrm{Bax} \mathrm{BH} 3$ peptide expressed and released into the tumor microenvironment via a liveattenuated bacterial vector, promoted apoptosis, induced antitumor activity, and increased survival in a murine xenograft model of human B non-Hodgkin's lymphoma [30]. However, the activity of the $\mathrm{BH} 3$ peptides from the proapoptotic Bak protein of the Bcl-2 family against hematologic malignant cells and particularly their ability to sensitize the cells to chemotherapy required further characterization. In this study, we evaluated the ability of the cell-permeable Bak BH3 peptide (PETK), constituted by the Bak BH3 peptide bound to the molecular Tag Flag and to the Antennapedia fusogenic peptide, to promote apoptosismediated cell death and to induce chemosensitization in hematologic malignant cells.

With molecular modeling, we documented that the PETK peptidic complex is characterized by the presence of two $\alpha$-helices connected by a loop. Figure 1(a) shows that the Bak BH3 peptide stabilizes a small $\alpha$-helix, as previously reported [13]. The molecular Tag Flag is part of the loop, and the Antennapedia fusogenic peptide stabilizes the major $\alpha$-helix, also as previously described [60]. The pleating and packing reveal a type bHLH structural domain. Evaluation of its stereochemical quality showed that $99.8 \%$ of the residues are in regions in which the $\varphi$ and $\psi$ angles correspond to pleating of the $\alpha$-helices. In terms of the theoretical prediction on the internalization of the core in the membrane, we observed that given its amino acid composition and its hydrophobicity, it is possible that it crosses the membrane through a diffusion process. With this information, the cell-permeable Bak BH3 peptide (PETK) and the PET and KT controls were synthesized. 
In order to analyze the effect of the cell-permeable Bak BH3 peptide on the viability of cell lines obtained from hematologic malignancies, Ramos cells from Burkitt's lymphoma, an aggressive human B non-Hodgkin's lymphoma expressing the $\mathrm{Bax}, \mathrm{Bak}, \mathrm{Bcl}^{-}{ }_{\mathrm{XL}}$, and $\mathrm{Mcl}-1$ proteins but not Bcl-2 (Figure 1(b)) and CCRF-CEM cells originating from human T-cell acute lymphoblastic leukemia and expressing $\mathrm{Bax}, \mathrm{Bak}$, and $\mathrm{Bcl}-{ }_{\mathrm{xL}}$ and slightly expressing $\mathrm{Bcl}-2$ and Mcl-1 also (Figure 1(b)), were treated with $20 \mu \mathrm{M}$ of the different peptides and controls. As seen in Figure 2(a), treatment with the cell-permeable $\mathrm{Bak} \mathrm{BH} 3$ peptide induced death in $38 \%$ of Ramos cells, $13 \%$ more than in the positive control, CDDP (a drug used in the treatment of chemotherapy-refractory hematologic neoplasias) $[45,46]$. As expected, treatment with the KT peptide that does not have the PE peptide to enter the cell showed cell death baseline values; surprisingly, in CCRF-CEM cells, we observed $74 \%$ cell death, $30 \%$ more than that observed with the positive control, CDDP (44\%). Assays with active caspase-3, conducted on Ramos and CCRF-CEM cells treated with the different peptides, confirmed the cell death induced by the cell-permeable Bak peptide and is due to the restoration of apoptosis mechanisms. Therefore, in Ramos cells, apoptosis mediated by the cell-permeable Bak peptide induced a fourfold increase in active caspase- 3 positive cells than those that were only treated with the KT peptide and other controls (Figure 2(b)). CCRF-CEM cells were more sensitive to the effect of the cell-permeable Bak $\mathrm{BH} 3$ peptide compared with the KT peptide and yielded 7 times more active caspase- 3 positive cells than those treated only with the KT peptide and other controls. This increased sensitivity to treatment with the cell-permeable Bak BH3 peptide in this cell line may be explained by the low expression of the antiapoptotic molecules Mcl-1 and Bcl-2 and proapoptotic Bax protein [61] (Figure 1(b)); unlike Ramos cells, CCRF-CEM cells express the Bcl-2 protein; but in pediatric patients with ALL, its presence has been shown to not condition therapeutic drug resistance $[62,63]$. In this differential activity of the cellpermeable Bak BH3 peptide among the Ramos and CCRFCEM cells, the fusogenic peptide also could affect the outcome, since it has been reported that the Antennapedia peptide is more efficiently imported into human primary T lymphocyte compared with human primary B lymphocyte [64]. However, these results are consistent with previous studies that used the cell-permeable Bak $\mathrm{BH} 3$ peptide to restore apoptosis in head and neck squamous cell carcinoma cells and in T-cell acute leukemia cells that overexpress antiapoptotic molecules belonging to the Bcl-2 family [28].

The administration of subtoxic drug doses in conjunction with molecules that sensitize cells to die by apoptosis and in particular, BH3-mimetic drugs, is one of the useful strategies to decrease side effects and improve results in patients with hematologic malignancies [15]. Accordingly, we analyzed the ability of the cell-permeable Bak $\mathrm{BH} 3$ peptide (PETK) to induce chemosensitivity, particularly to cisplatin (CDDP), a drug used as alternative treatment in cases of refractory hematologic malignancies $[45,46]$. Results in Figure 3 confirm that treatment of Ramos cells with PETK in combination with CDDP induced $62 \%$ of cell death and 39\% apoptosis, compared with only PETK therapy (38\% cell death and 20\% apoptosis) and only CDDP (24\% cell death and $14 \%$ apoptosis). These values were even greater in the chemosensitization observed in CCRF-CEM cells, in which the combination of PETK and CDDP led to $80 \%$ cell death and $64 \%$ apoptosis, compared with treatment with only PETK (64\% viability and $45 \%$ apoptosis) and only CDDP (44\% cell death and $26 \%$ apoptosis). These data are consistent with the increased antitumor activity of ABT-737 and its orally bioavailable derivative, navitoclax, when combined with different chemotherapeutic agents (dexamethasone, etoposide, fludarabine, vincristine, and doxorubicin among others) and used in the treatment of different tumor cell lines [56], including chemotherapy-resistant leukemias [65, 66] and lymphomas [67]. In the same context, venetoclax, an orally bioavailable $\mathrm{Bcl}-2$-specific $\mathrm{BH} 3 \mathrm{mi}$ metic, has shown greater efficacy when combined with chemotherapies such as $\mathrm{CHOP}, \mathrm{R}-\mathrm{CHOP}$, or bendamustine among others, in patients with relapsed or refractory nonHodgkin's lymphoma $[66,68]$. However, these encouraging results with synthetic $\mathrm{BH} 3$ mimetics, such as venetoclax, are often associated with severe decrease in lymphocyte counts and tumor lysis syndrome, a risk that has been mitigated by dose deescalation $[15,55,69]$.

Since the Bak BH3 peptide has mostly been reported to bind $\mathrm{Bcl}_{-\mathrm{XL}}, \mathrm{Mcl}-1$, and $\mathrm{A} 1$ antiapoptotic proteins and that the Bax BH3 peptide binds to Bcl-2, Bcl-w, and $\mathrm{A} 1$ antiapoptotic proteins [70], we decided to combine the treatment with both $\mathrm{BH} 3$ peptides to better antagonize the complete set of antiapoptotic proteins overexpressed in hematologic malignant cells [71, 72]. Accordingly, Ramos and CCRF-CEM cells were treated with different peptides at $20 \mu \mathrm{M}$, and the results shown in Figure 4(a) reveal that cellpermeable Bax $\mathrm{BH} 3$ peptide was more potent to reduce the viability compared with the cell-permeable $\mathrm{Bak} \mathrm{BH} 3$ peptide in both cell lines tested. Since the PEX, used in this study, does not have the Flag peptide included in the PETK, the differences in the design could suggest that the cell-permeable Bak BH3 peptide should be designed in a better manner to enhance its activity. However, it has been reported that the cell-permeable $\mathrm{Bax} \mathrm{BH} 3$ peptide is also more potent to induce death of head and neck squamous carcinoma cells comparing with cell-permeable Bak peptide, even though when both cell-permeable peptides had the same design (Antennapedia peptide in the amino-terminal domain, without the flag sequence) [28]. Figure 4(a) also reveals a surprising synergistic effect when combining the cellpermeable BH3 peptides PETK and PEX that induced cell death in $79 \%$ of Ramos cells and in $90 \%$ of CCFR-CEM cells; this cell death percentage is even greater than that obtained with the combination of the cell-permeable $\mathrm{BH} 3$ peptides with CDDP in previously described experiments. These data are consistent with previous studies showing that the combination of the $\mathrm{BH} 3$ peptides from $\mathrm{BH} 3$-only proapoptotic proteins act synergistically in the induction of apoptosis in neuroblastoma cells [73] and in chronic lymphocytic leukemia [74]. Similar results have been obtained with combinations of $\mathrm{BH} 3$ mimetic drugs in hematologic malignances [75-80]. Notably, the use of the 
PETK and PEX peptides induced slight toxicity on PBMC (Figure 4(b)). This reduced toxicity on PBMC is consistent with previous observations claiming that tumor cells have more sensitivity to an apoptotic stimulus comparing with normal cells, due to the "Mitochondrial priming" [81, 82], which means the proximity of a cell to the apoptosis threshold, a condition that is regulated by the balance of the antiapoptotic and proapoptotic proteins of the Bcl-2 family. Mitochondrial priming is relative, and the more primed a cell becomes, the lower the apoptotic threshold and tolerance for apoptotic stimuli. In this context, cancers are highly primed compared with the normal cells $[82,83]$, as has been determined by the $\mathrm{BH} 3$ profiling, an assay that measure the proximity of a cell to the apoptosis threshold, and also identifies the specific prosurvival proteins on which a cell depends for its survival [84].

Despite these encouraging results, it is important to mention that PETK and PEX combination treatment led to decreased viability of PBMCs at comparable levels to CDDP treatment. Although this effect was less impressive compared to lymphoma and leukemia cells, it could have implications in the therapeutic window of the peptides, as was observed for the dual Bcl-2/Bcl-xL inhibitor ABT-737 and its orally bioavailable equivalent ABT-263 (Navitoclax), that showed thrombocytopenia due to inhibition of Bcl-xL [84]. However, it has been also reported that the first selective and highly potent $\mathrm{Bcl}-2$ inhibitor, venetoclax (formerly ABT199/GDC-0199), induced significantly less thrombocytopenia than navitoclax [44], although this BH3 mimetic showed significant toxicities on normal human B cells as their malignant counterpart [80]. In this context, a further characterization is needed with the PETK and PEX combination treatment, to elucidate the complete effect over normal cells; for instance, perform a $\mathrm{BH} 3$ profile determination or make dose reductions in our assays, since our results in the Figure 5 showed that less amount on the PETK and PEX combinations ( $20 \mu \mathrm{M}$ and $5 \mu \mathrm{M}$, respectively) still induced a significant reduction in the viability of the Ramos and CCFR-CEM cells.

Finally, we decided to determine whether the combination of the PETK and PEX peptides that inhibit several antiapoptotic proteins induced greater chemosensitization than that observed with a single peptide. Based on that aim, Ramos and CCRF-CEM cells were treated for 6 hrs with the PET, KT, and PETK peptides at $20 \mu \mathrm{M}$ and with the $\mathrm{X}$ and PEX peptides at $5 \mu \mathrm{M}$ (the peptide dose was decreased to underscore the synergistic effect on the induction of cell death in tumor cells), in the presence and in the absence of subtoxic doses of vincristine $80 \mathrm{nM}$, a commonly used drug in the treatment of hematological malignancies [50]. Figure 5 shows that the combination of the cell-permeable Bak $\mathrm{BH} 3$ peptide (PETK) with the cell-permeable $\mathrm{Bax} \mathrm{BH} 3$ peptide (PEX) eliminated $51 \%$ of the Ramos cells and $68 \%$ of the CCRF-CEM cells; as expected, in the presence of vincristine, cell death increased significantly to $71 \%$ in Ramos cells and $82 \%$ in CCRF-CEM cells. These results suggest that treatment with the $\mathrm{BH} 3$ peptide combination has great potential in the chemosensitization of hematologic malignant cells, as has been shown with the $\mathrm{BH} 3$ mimetic drugs
[15], and the use of subtoxic doses of vincristine with prior sensitization with $\mathrm{BH} 3$ peptide combinations would solve the problem of neurotoxicity associated with its administration in large doses in patients with hematologic malignancies [85].

\section{Conclusions}

Overall, our findings have shown the ability of the Bak BH3 peptide coupled with the Antennapedia fusogenic peptide (cell-permeable Bak BH3 peptide) to restore apoptosis and induce chemosensitization in acute lymphoblastic leukemia and non-Hodgkin's lymphoma cell lines, which may be further enhanced with the addition of the cell-permeable Bax $\mathrm{BH} 3$ peptide. These results represent an attractive approach to the improvement in patient outcomes, in cases of relapsed or refractory hematological malignant cells.

\section{Data Availability}

The data used to support the findings of this study are available from the corresponding author upon reasonable request.

\section{Conflicts of Interest}

The authors declare that they have no conflicts of interest.

\section{Acknowledgments}

The authors would like to thank Daniel D. Hernández-Cueto for his excellent technical assistance. RL-P would like to thank the funding of this project through the supports of CONACYT (CB-2013-01-222446 and INFR-2015-01255341) and Federal Funds (HIM-2015-049 SSA. 1217 and HIM-2017-024 SSA. 1332).

\section{References}

[1] F. Bray, J. Ferlay, I. Soerjomataram, R. L. Siegel, L. A. Torre, and A. Jemal, "Global cancer statistics 2018: GLOBOCAN estimates of incidence and mortality worldwide for 36 cancers in 185 countries," CA: A Cancer Journal for Clinicians, vol. 68, no. 6 , pp. 394-424, 2018.

[2] A. Miranda-Filho, M. Piñeros, A. Znaor, R. Marcos-Gragera, E. Steliarova-Foucher, and F. Bray, "Global patterns and trends in the incidence of non-Hodgkin lymphoma," Cancer Causes \& Control, vol. 30, no. 5, pp. 489-499, 2019.

[3] S. H. Swerdlow, E. Campo, N. L. Harris, E. S. Jaffe, S. A. Pileri, H. Stein, J. Thiele, WHO Classification of Tumours of Haematopoietic and Lymphoid Tissues, Vol. 2, International Agency for Research on Cancer, Lyon, France, 4th edition, 2017.

[4] A. Jemal, E. M. Ward, C. J. Johnson et al., "Annual report to the nation on the status of cancer, 1975-2014, featuring survival," JNCI: Journal of the National Cancer Institute, vol. 109, no. 9, 2017.

[5] C. Allemani, T. Matsuda, V. Di Carlo et al., "Global surveillance of trends in cancer survival 2000-14 (CONCORD-3): analysis of individual records for 37513025 patients diagnosed with one of 18 cancers from 322 population-based 
registries in 71 countries," The Lancet, vol. 391, no. 10125, pp. 1023-1075, 2018.

[6] D. Chihara, Y. Oki, M. A. Fanale et al., "Stage I non-Hodgkin lymphoma: no plateau in disease-specific survival?" Annals of Hematology, vol. 98, no. 5, pp. 1169-1176, 2019.

[7] J. O. Armitage, R. D. Gascoyne, M. A. Lunning, and F. Cavalli, "Non-Hodgkin lymphoma," The Lancet, vol. 390, no. 10091, pp. 298-310, 2017.

[8] M. J. Barth and V. Minard-Colin, "Novel targeted therapeutic agents for the treatment of childhood, adolescent and young adult non-Hodgkin lymphoma," British Journal of Haematology, vol. 185, no. 6, pp. 1111-1124, 2019.

[9] A. A. Stavrovskaya, "Cellular mechanisms of multidrug resistance of tumor cells," Biochemistry, vol. 65, no. 1, pp. 95$106,2000$.

[10] R. W. Johnstone, A. A. Ruefli, and S. W. Lowe, "Apoptosis: a link between cancer genetics and chemotherapy," Cell, vol. 108, no. 2, pp. 153-164, 2002.

[11] D. Westphal, G. Dewson, P. E. Czabotar, and R. M. Kluck, "Molecular biology of Bax and Bak activation and action," Biochimica et Biophysica Acta (BBA)-Molecular Cell Research, vol. 1813, no. 4, pp. 521-531, 2011.

[12] T. T. Renault and S. Manon, "Bax: addressed to kill," Biochimie, vol. 93, no. 9, pp. 1379-1391, 2011.

[13] A. M. Petros, E. T. Olejniczak, and S. W. Fesik, "Structural biology of the Bcl-2 family of proteins," Biochimica et Biophysica Acta (BBA)-Molecular Cell Research, vol. 1644, no. 23, pp. 83-94, 2004.

[14] G. Häcker and A. Weber, "BH3-only proteins trigger cytochrome c release, but how?" Archives of Biochemistry and Biophysics, vol. 462, no. 2, pp. 150-155, 2007.

[15] D. Merino, G. L. Kelly, G. Lessene, A. H. Wei, A. W. Roberts, and A. Strasser, "BH3-Mimetic drugs: blazing the trail for new cancer medicines," Cancer Cell, vol. 34, no. 6, pp. 879-891, 2018.

[16] T. Knight, D. Luedtke, H. Edwards, J. W. Taub, and Y. Ge, “A delicate balance-the BCL-2 family and its role in apoptosis, oncogenesis, and cancer therapeutics," Biochemical Pharmacology, vol. 162, pp. 250-261, 2019.

[17] T. Miyashita and J. C. Reed, "Bcl-2 oncoprotein blocks chemotherapy-induced apoptosis in a human leukemia cell line," Blood, vol. 81, no. 1, pp. 151-157, 1993.

[18] A. Bonetti, M. Zaninelli, R. Leone et al., "Bcl-2 but not p53 expression is associated with resistance to chemotherapy in advanced breast cancer," Clinical Cancer Research: An Official Journal of the American Association for Cancer Research, vol. 4, no. 10, pp. 2331-2336, 1998.

[19] E. Wesarg, S. Hoffarth, R. Wiewrodt et al., "Targeting Bcl-2 family proteins to overcome drug resistance in non-small cell lung cancer," International Journal of Cancer, vol. 121, no. 11, pp. 2387-2394, 2007.

[20] D. J. Wallace, D. Shen, G. F. Reed et al., "Detection of thebcl$2 t(14 ; 18)$ translocation and proto-oncogene expression in primary intraocular lymphoma," Investigative Opthalmology \& Visual Science, vol. 47, no. 7, pp. 2750-2756, 2006.

[21] J. R. Goodlad, P. J. Batstone, D. A. Hamilton, N. M. Kernohan, D. A. Levison, and J. M. White, "Bcl-2 gene abnormalities define distinct clinical subsets of follicular lymphoma," Histopathology, vol. 49, no. 3, pp. 229-241, 2006.

[22] F. Habens, A. S. Lapham, C. L. Dallman et al., "Distinct promoters mediate constitutive and inducible Bcl-XL expression in malignant lymphocytes," Oncogene, vol. 26, no. 13, pp. 1910-1919, 2007.
[23] M. A. Hernandez-Luna, L. Rocha-Zavaleta, M. I. Vega, and S. Huerta-Yepez, "Hypoxia inducible factor-1alpha induces chemoresistance phenotype in non-Hodgkin lymphoma cell line via up-regulation of Bcl-(xL)," Leukemia \& Lymphoma, vol. 54, no. 5, pp. 1048-1055, 2012.

[24] E. P. Holinger, T. Chittenden, and R. J. Lutz, "Bak BH3 peptides antagonize Bcl-xL function and induce apoptosis through cytochromec-independent activation of caspases," Journal of Biological Chemistry, vol. 274, no. 19, pp. 1329813304, 1999.

[25] C. Moreau, P.-F. Cartron, A. Hunt et al., "Minimal BH3 peptides promote cell death by antagonizing anti-apoptotic proteins," Journal of Biological Chemistry, vol. 278, no. 21, pp. 19426-19435, 2003.

[26] P. E. Czabotar, E. F. Lee, M. F. van Delft et al., "Structural insights into the degradation of Mcl-1 induced by $\mathrm{BH} 3$ domains," Proceedings of the National Academy of Sciences, vol. 104, no. 15, pp. 6217-6222, 2007.

[27] S. Shangary and D. E. Johnson, "Peptides derived from BH3 domains of Bcl-2 family members: a comparative analysis of inhibition of Bcl-2, Bcl-xLand Bax oligomerization, induction of Cytochromec Release, and activation of cell death†," Biochemistry, vol. 41, no. 30, pp. 9485-9495, 2002.

[28] R. Li, A. L. Boehm, M. B. Miranda, S. Shangary, J. R. Grandis, and D. E. Johnson, "Targeting antiapoptotic Bcl-2 family members with cell-permeable $\mathrm{BH} 3$ peptides induces apoptosis signaling, death in head, neck squamous cell carcinoma cells," Neoplasia, vol. 9, no. 10, pp. 801-IN1, 2007.

[29] M. A. Hernández-Luna, R. Díaz de León-Ortega, D. D. HernándezCueto et al., "Bactofection of sequences encoding a Bax protein peptide chemosensitizes prostate cancer tumor cells," Boletín Médico Del Hospital Infantil de México (English Edition), vol. 73, no. 6, pp. 388-396, 2016.

[30] A. A. Mateos-Chavez, P. Munoz-Lopez, E. I. Becerra-Baez et al., "Live attenuated Salmonella enterica expressing and releasing cell-permeable $\mathrm{Bax} \mathrm{BH} 3$ peptide through the MisL autotransporter system elicits antitumor activity in a murine Xenograft model of human B non-hodgkin's lymphoma," Frontiers in Immunology, vol. 10, p. 2562, 2019.

[31] A. Waterhouse, M. Bertoni, S. Bienert et al., "SWISS-MODEL: homology modelling of protein structures and complexes," Nucleic Acids Research, vol. 46, no. W1, pp. W296-W303, 2018.

[32] S. Lepore, A. Waterhouse, T. A. P. de Beer et al., "The SWISSMODEL Repository-new features and functionality," Nucleic Acids Research, vol. 45, no. D1, pp. D313-D319, 2017.

[33] A. Sali and T. L. Blundell, "Comparative protein modelling by satisfaction of spatial restraints," Journal of Molecular Biology, vol. 234, no. 3, pp. 779-815, 1993.

[34] N. Eswar, B. Webb, M. A. Marti-Renom et al., "Comparative protein structure modeling using Modeller," Current Protocols in Protein Science, vol. 15, no. 1, 2006.

[35] J. Huang, S. Rauscher, G. Nawrocki et al., "CHARMM36m: an improved force field for folded and intrinsically disordered proteins," Nature Methods, vol. 14, no. 1, pp. 71-73, 2017.

[36] W. L. Jorgensen, J. Chandrasekhar, J. D. Madura, R. W. Impey, and M. L. Klein, "Comparison of simple potential functions for simulating liquid water," The Journal of Chemical Physics, vol. 79, no. 2, pp. 926-935, 1983.

[37] P. Eastman, J. Swails, J. D. Chodera et al., “OpenMM 7: rapid development of high performance algorithms for molecular dynamics," PLOS Computational Biology, vol. 13, no. 7, Article ID e1005659, 2017. 
[38] V. B. Chen, W. B. Arendall III, J. J. Headd et al., "MolProbity: all-atom structure validation for macromolecular crystallography," Acta Crystallographica Section D Biological Crystallography, vol. 66, no. 1, pp. 12-21, 2010.

[39] S. C. Lovell, I. W. Davis, W. B. Arendall III et al., "Structure validation by $C \alpha$ geometry: $\phi, \psi$ and $C \beta$ deviation," Proteins: Structure, Function, and Bioinformatics, vol. 50, no. 3, pp. 437-450, 2003.

[40] K. Uziela, N. Shu, B. Wallner, and A. Elofsson, "ProQ3: improved model quality assessments using Rosetta energy terms," Scientific Reports, vol. 6, no. 1, p. 33509, 2016.

[41] K. Uziela, D. Menendez Hurtado, N. Shu, B. Wallner, and A. Elofsson, "ProQ3D: Improved model quality assessments using deep learning," Bioinformatics, vol. 33, no. 10, pp. 1578-1580, 2017.

[42] P. Benkert, M. Künzli, and T. Schwede, "QMEAN server for protein model quality estimation," Nucleic Acids Research, vol. 37, no. 2, pp. W510-W514, 2009.

[43] R. Luria-Perez, L. Cedillo-Barron, L. Santos-Argumedo, V. F. Ortiz-Navarrete, A. Ocaña-Mondragon, and C. R. GonzalezBonilla, "A fusogenic peptide expressed on the surface of Salmonella enterica elicits CTL responses to a dengue virus epitope," Vaccine, vol. 25, no. 27, pp. 5071-5085, 2007.

[44] A. J. Souers, J. D. Leverson, E. R. Boghaert et al., “ABT-199, a potent and selective BCL-2 inhibitor, achieves antitumor activity while sparing platelets," Nature Medicine, vol. 19, no. 2, pp. 202-208, 2013.

[45] M. Huang, T. Baetz, S. Couban et al., "Gemcitabine, dexamethasone, and cisplatin in patients with recurrent or refractory aggressive histology B-cell non-Hodgkin lymphoma: a Phase II study by the National Cancer Institute of Canada Clinical Trials Group (NCIC-CTG)," Cancer, vol. 101, no. 8, pp. 1835-1842, 2004.

[46] K. Paul, S. Katragadda, D. Ponce, M. Rasul, and N. Ahmed, "Temozolomide and cisplatin in relapsed/refractory acute leukemia," Journal of Hematology \& Oncology, vol. 2, no. 1, p. 21, 2009.

[47] J. Long, L. Liu, Z. Nikolovska-Coleska et al., "Optimization and validation of mitochondria-based functional assay as a useful tool to identify BH3-like molecules selectively targeting anti-apoptotic Bcl-2 proteins," BMC Biotechnology, vol. 13, no. 1, p. 45, 2013.

[48] M. Milani, D. P. Byrne, G. Greaves et al., "DRP-1 is required for $\mathrm{BH} 3$ mimetic-mediated mitochondrial fragmentation and apoptosis," Cell Death \& Disease, vol. 8, no. 1, Article ID e2552, 2017.

[49] L. Chen, S. N. Willis, A. Wei et al., "Differential targeting of prosurvival $\mathrm{Bcl}-2$ proteins by their $\mathrm{BH} 3$-only ligands allows complementary apoptotic function," Molecular Cell, vol. 17, no. 3, pp. 393-403, 2005.

[50] B. De Moerloose, S. Suciu, Y. Bertrand et al., "Improved outcome with pulses of vincristine and corticosteroids in continuation therapy of children with average risk acute lymphoblastic leukemia (ALL) and lymphoblastic nonHodgkin lymphoma (NHL): report of the EORTC randomized phase 3 trial 58951," Blood, vol. 116, no. 1, pp. 36-44, 2010.

[51] Y. P. Munzer, H. Alias, and R. Jamal, "Meta-analysis of gene expression in relapsed childhood B-acute lymphoblastic leukemia," BMC Cancer, vol. 17, no. 1, p. 120, 2017.

[52] N. Daver and F. Ravandi, "Enhancing cytotoxicity of immunotoxins in AML," Blood, vol. 127, no. 23, pp. 2787-2788, 2016.
[53] K. Kuramoto, A. Sakai, K. Shigemasa et al., "High expression of MCL1 gene related to vascular endothelial growth factor is associated with poor outcome in non-Hodgkin's lymphoma," British Journal of Haematology, vol. 116, no. 1, pp. 158-161, 2002.

[54] J. L. Katoh, S. G. Katz, G. H. Bird et al., "A stapled BIM peptide overcomes apoptotic resistance in hematologic cancers," Journal of Clinical Investigation, vol. 122, no. 6, pp. 2018-2031, 2012.

[55] C. M. Adams, S. Clark-Garvey, P. Porcu, and C. M. Eischen, "Targeting the Bcl-2 family in B cell lymphoma," Frontiers in Oncology, vol. 8, p. 636, 2018.

[56] T. Oltersdorf, S. W. Elmore, A. R. Shoemaker et al., "An inhibitor of Bcl-2 family proteins induces regression of solid tumours," Nature, vol. 435, no. 7042, pp. 677-681, 2005.

[57] L. Joseph, M. Gonen, G. Bhagat et al., "The BH3-only mimetic ABT-737 synergizes the antineoplastic activity of proteasome inhibitors in lymphoid malignancies," Blood, vol. 112, no. 7, pp. 2906-2916, 2008.

[58] A. W. Roberts, J. F. Seymour, J. R. Brown et al., "Substantial susceptibility of chronic lymphocytic leukemia to Bcl-2 inhibition: results of a phase I study of Navitoclax in patients with relapsed or refractory disease," Journal of Clinical Oncology, vol. 30, no. 5, pp. 488-496, 2012.

[59] J. J. Cui, J. Kuruvilla, D. Mendelson et al., "Phase I dose finding studies of obatoclax (GX15-070), a small molecule pan-Bcl-2 family antagonist, in patients with advanced solid tumors or lymphoma," Clinical Cancer Research, vol. 16, no. 15, pp. 4038-4045, 2010.

[60] D. Derossi, A. H. Joliot, G. Chassaing, and A. Prochiantz, "The third helix of the Antennapedia homeodomain translocates through biological membranes," The Journal of Biological Chemistry, vol. 269, no. 14, pp. 10444-10450, 1994.

[61] H. W. Findley, L. Gu, A. M. Yeager, and M. Zhou, "Expression and regulation of Bcl-2, Bcl-xl, and Bax correlate with p53 status and sensitivity to apoptosis in childhood acute lymphoblastic leukemia," Blood, vol. 89, no. 8, pp. 2986-2993, 1997.

[62] J. L. Gala, C. Vermylen, G. Cornu et al., "High expression of $\mathrm{Bcl}-2$ is the rule in acute lymphoblastic leukemia, except in Burkitt subtype at presentation, and is not correlated with the prognosis," Annals of Hematology, vol. 69, no. 1, pp. 17-24, 1994.

[63] E. Coustan-Smith, A. Kitanaka, C. Pui et al., "Clinical relevance of Bcl-2 overexpression in childhood acute lymphoblastic leukemia," Blood, vol. 87, no. 3, pp. 1140-1146, 1996.

[64] M. Fenton, N. Bone, and A. J. Sinclair, "The efficient and rapid import of a peptide into primary B and T lymphocytes and a lymphoblastoid cell line," Journal of Immunological Methods, vol. 212, no. 1, pp. 41-48, 1998.

[65] K. D. Mason, S. L. Khaw, K. C. Rayeroux et al., "The BH3 mimetic compound, ABT-737, synergizes with a range of cytotoxic chemotherapy agents in chronic lymphocytic leukemia," Leukemia, vol. 23, no. 11, pp. 2034-2041, 2009.

[66] L. M. Roberts, B. Szymanska, U. Wilczynska-Kalak et al., "The Bcl-2 homology domain 3 mimetic ABT-737 targets the apoptotic machinery in acute lymphoblastic leukemia resulting in synergistic in vitro and in vivo interactions with established drugs," Molecular Pharmacology, vol. 77, no. 3, pp. 483-494, 2010.

[67] C. Tse, A. R. Shoemaker, J. Adickes et al., "ABT-263: a potent and orally bioavailable Bcl-2 family inhibitor," Cancer Research, vol. 68, no. 9, pp. 3421-3428, 2008. 
[68] S. Roberts, L. J. Swinnen, D. Wang et al., "Venetoclax, bendamustine, and rituximab in patients with relapsed or refractory NHL: a phase Ib dose-finding study," Annals of Oncology, vol. 29, no. 9, pp. 1932-1938, 2018.

[69] A. W. Ross, M. S. Davids, J. M. Pagel et al., "Targeting Bcl-2 with venetoclax in relapsed chronic lymphocytic leukemia," New England Journal of Medicine, vol. 374, no. 4, pp. 311-322, 2016.

[70] B. Wong, C. Liang, J. U. Jung, and B.-H. Oh, "Evidence that inhibition of BAX activation by Bcl-2 involves its tight and preferential interaction with the $\mathrm{BH} 3$ domain of BAX," Cell Research, vol. 21, no. 4, pp. 627-641, 2011.

[71] M. H. Kang, Z. Wan, Y. H. Kang, R. Sposto, and C. P. Reynolds, "Mechanism of synergy of N-(4-hydroxyphenyl)retinamide and ABT-737 in acute lymphoblastic leukemia cell lines: Mcl-1 inactivation," JNCI: Journal of the National Cancer Institute, vol. 100, no. 8, pp. 580-595, 2008.

[72] C. Stolz, G. Hess, P. S. Hähnel et al., "Targeting Bcl-2 family proteins modulates the sensitivity of B-cell lymphoma to rituximab-induced apoptosis," Blood, vol. 112, no. 8, pp. 3312-3321, 2008.

[73] K. C. Goldsmith, X. Liu, V. Dam et al., "BH3 peptidomimetics potently activate apoptosis and demonstrate single agent efficacy in neuroblastoma," Oncogene, vol. 25, no. 33, pp. 4525-4533, 2006.

[74] M. Butterworth, A. Pettitt, S. Varadarajan, and G. M. Cohen, "BH3 profiling and a toolkit of $\mathrm{BH} 3$-mimetic drugs predict anti-apoptotic dependence of cancer cells," British Journal of Cancer, vol. 114, no. 6, pp. 638-641, 2016.

[75] S. K. Tahir, M. L. Smith, P. Hessler et al., "Potential mechanisms of resistance to venetoclax and strategies to circumvent it," BMC Cancer, vol. 17, no. 1, p. 399, 2017.

[76] T.-C. Teh, N.-Y. Nguyen, D. M. Moujalled et al., "Enhancing venetoclax activity in acute myeloid leukemia by co-targeting MCL1," Leukemia, vol. 32, no. 2, pp. 303-312, 2018.

[77] S. Thompson, S. P. Brown, B. Belmontes et al., "AMG 176, a selective MCL1 inhibitor, is effective in hematologic cancer models alone and in combination with established therapies," Cancer Discovery, vol. 8, no. 12, pp. 1582-1597, 2018.

[78] D. M. Moujalled, G. Pomilio, C. Ghiurau et al., "Combining BH3-mimetics to target both $\mathrm{Bcl}-2$ and MCL1 has potent activity in pre-clinical models of acute myeloid leukemia," Leukemia, vol. 33, no. 4, pp. 905-917, 2019.

[79] H. E. Lan, M. A. Fischer, T. Lee et al., "A novel MCL1 inhibitor combined with venetoclax rescues venetoclax-resistant acute myelogenous leukemia," Cancer Discovery, vol. 8, no. 12, pp. 1566-1581, 2018.

[80] S. L. Ayers, D. Mérino, M. A. Anderson et al., "Both leukaemic and normal peripheral B lymphoid cells are highly sensitive to the selective pharmacological inhibition of prosurvival Bcl-2 with ABT-199," Leukemia, vol. 28, no. 6, pp. 1207-1215, 2014.

[81] M. Certo, V. D. G. Moore, M. Nishino et al., "Mitochondria primed by death signals determine cellular addiction to antiapoptotic Bcl-2 family members," Cancer Cell, vol. 9, no. 5, pp. 351-365, 2006.

[82] T. N. Chonghaile, K. A. Sarosiek, T.-T. Vo et al., "Pretreatment mitochondrial priming correlates with clinical response to cytotoxic chemotherapy," Science, vol. 334, no. 6059, pp. 1129-1133, 2011.

[83] S. Mitsiades, C. D. Zimberlin, E. Fessler et al., "Decreased mitochondrial priming determines chemoresistance of colon cancer stem cells," Cell Death \& Differentiation, vol. 21, no. 7, pp. 1170-1177, 2014.
[84] R. Valentin, S. Grabow, and M. S. Davids, "The rise of apoptosis: targeting apoptosis in hematologic malignancies," Blood, vol. 132, no. 12, pp. 1248-1264, 2018.

[85] M. L. Madsen, H. Due, N. Ejskjær, P. Jensen, J. Madsen, and K. Dybkær, "Aspects of vincristine-induced neuropathy in hematologic malignancies: a systematic review," Cancer Chemotherapy and Pharmacology, vol. 84, no. 3, pp. 471-485, 2019. 